\title{
Cost-Effectiveness of Elective Laparoscopic Cholecystectomy vs. Observation in Older Patients Presenting with Mild Biliary Disease $^{\star}$
}

\author{
Abhishek D. Parmar, MD, MS ${ }^{1,2}$, Mark D. Coutin, BA ${ }^{1}$, Gabriela M. Vargas, MD, MS ${ }^{1}$, Nina P. \\ Tamirisa, MD ${ }^{1,2}$, Kristin M. Sheffield, PhD $^{1}$, and Taylor S. Riall, MD, PhD1 \\ ${ }^{1}$ Departments of Surgery, The University of Texas Medical Branch, Galveston, Texas \\ ${ }^{2}$ The University of California, San Francisco-East Bay, Oakland, California
}

\begin{abstract}
INTRODUCTION-Our objective was to determine the probability threshold for recurrent symptoms at which elective cholecystectomy compared to observation in older patients with symptomatic cholelithiasis is the more effective and cost-effective option.

METHODS-We built a decision model of elective cholecystectomy vs. observation in patients $>65$ presenting with initial episodes of symptomatic cholelithiasis that did not require initial hospitalization or cholecystectomy. Probabilities for subsequent hospitalization, emergency cholecystectomy, and perioperative complications were based on previously published probabilities from a 5\% national sample of Medicare patients. Costs were estimated from Medicare reimbursements and from the Healthcare Cost and Utilization Project. Utilities (qualityadjusted life years, QALYs) were obtained from established literature estimates.

RESULTS-Elective cholecystectomy compared to observation in all patients was associated with lower effectiveness ( -0.10 QALYs) and had an increased cost of $\$ 3,422.83$ per patient at two years follow-up. Elective cholecystectomy became the more effective option when the likelihood for continued symptoms exceeded $45.3 \%$. Elective cholecystectomy was both more effective and less costly when the probability for continued symptoms exceeded $82.7 \%$.
\end{abstract}

CONCLUSION-An individualized shared decision-making strategy based on these data can increase elective cholecystectomy rates in patients at high risk for recurrent symptoms and minimize unnecessary cholecystectomy for patients unlikely to benefit.

\section{Keywords}

cholelithiasis; cholecystectomy; cost-benefit analysis

\footnotetext{
* Presented at the $55^{\text {th }}$ Annual Meeting of the Society for Surgery of the Alimentary Tract at Digestive Diseases Week, May $5^{\text {th }}, 2014$ Corresponding Author: Taylor S. Riall, MD, PhD, Department of Surgery, University of Texas Medical Branch, 301 University Boulevard, Galveston, TX 77555-0541, Phone: 409-772-1836, Fax: 409-747-2253, tsriall@utmb.edu.
} 


\section{INTRODUCTION}

The prevalence of gallstones increases with age. Fifty-seven percent of women 70-79 years have a history of cholecystectomy or sonographic evidence of gallstones. ${ }^{1,2}$ In addition, the development of symptoms and complications related to gallstones increase with age. In older patients, who represent an expanding population in need of surgical care, gallstone disease is the most common indication for abdominal surgery. ${ }^{3}$

Based on a 1992 National Institutes of Health Consensus Statement, elective laparoscopic cholecystectomy is the recommended treatment for patients with symptomatic cholelithiasis and few relative or absolute contraindications. ${ }^{4,5}$ However, the decision to perform cholecystectomy in older patients is complicated by the presence of decreased functional reserve, associated medical comorbidities, and prior complicated surgical history. Therefore, despite recommendations for cholecystectomy, previous data have demonstrated that cholecystectomy rates in older patients with symptomatic gallstones are low. ${ }^{6-9}$ However, the need for cholecystectomy in older patients undergoing observation is also low, ranging from $1.2-30 \% .^{1,8-12}$

Since the implementation of the Affordable Care Act, increased attention has been focused on the adoption of more cost-effective treatment strategies, particularly for patients with surgical disease. ${ }^{13}$ In this increasingly cost conscious environment and amidst an expanding older patient population, ${ }^{14}$ cost-effectiveness analysis seeks to provide a solution for allocating medical resources efficiently and achieve the best possible patient outcomes. Cost-effectiveness analysis takes into account patient preferences for various health states, conventional measures of outcomes including morbidity and mortality, and cost. These patient preferences for various health states can then be used to determine quality-adjusted life years (QALYs), a common metric that not only measures the burden of disease but also balances the quality and quantity of life lived.

We used probability estimates from a prior study using Medicare claims data ${ }^{12}$ to devise a decision model for patients older than 65 presenting with an initial episode of symptomatic cholelithiasis not requiring initial hospitalization or cholecystectomy. The decision tree model has two options: 1) perform early elective cholecystectomy in all patients or 2) observe all patients. Our objective was to determine the threshold for probability of recurrent symptoms at which elective cholecystectomy became the more effective and costeffective option for these patients.

\section{MATERIALS AND METHODS}

This study was determined to be exempt from review by the University of Texas Medical Branch Institutional Review Board.

\section{Base Case Decision Model}

A schematic of our decision model is shown in Figure 1. Our base case was a patient $>65$ presenting with an episode of symptomatic cholelithiasis who did not require immediate hospitalization or cholecystectomy. We developed a decision model for the initial treatment 
strategy including two treatment options: 1) early elective cholecystectomy in all patients or

2) observation in all patients.

\section{Probabilities (Table 1)}

Data from a previous study using a 5\% sample of Medicare claims from 1995-2007 were used to determine the probabilities for our model. ${ }^{12}$ This study identified over 117,000 patients with a diagnosis of symptomatic cholelithiasis. For the patients who did not undergo initial elective cholecystectomy, the study recorded the observed percentages of patients who experienced: 1) multiple emergency department (ED) or physician (MD) visits without hospitalization, 2) emergent gallstone-related hospitalization, or 3) no gallstone-related outpatient or inpatient visits in a two-year follow-up period. In addition, this analysis reported the percentage of patients who experienced in-hospital morbidity and mortality after emergent gallstone-related admission and, if cholecystectomy was performed, postoperative morbidity and mortality. These observed percentages comprised the probability estimates for our model. For the elective cholecystectomy group, we included probabilities for postoperative morbidity and mortality obtained from the literature. For the observation group, the following probabilities were included in the decision analysis: the probability of continued symptoms, the probability of hospitalization given continued symptoms, the probabilities of in-hospital morbidity and in-hospital mortality, the probabilities of emergent cholecystectomy and morbidity/mortality following emergent cholecystectomy.

\section{Costs (Table 1)}

Cost estimates were obtained from the Agency for Healthcare Research and Quality's Healthcare Cost and Utilization Project (HCUP) data as published on HCUPnet. ${ }^{15}$ HCUPnet compiles data from HCUP's Nationwide Inpatient Sample and provides vital statistical hospital admissions data, stratifying mean annual procedural costs by patient and hospital demographics and year. We used mean 2011 costs based on disease-related groups (DRGs) for patients aged 65-84 for our study. For inpatient admissions with cholecystectomy, we used DRG codes for open cholecystectomy without complications (416), open cholecystectomy with minor complications (415), open cholecystectomy with major complications (414), laparoscopic cholecystectomy without complications (419), laparoscopic cholecystectomy with minor complications (418), and laparoscopic cholecystectomy with major complications (417) for patients undergoing cholecystectomy. For hospital admissions without cholecystectomy, we used DRGs for biliary tract admission (446), biliary tract admission with minor complications (445), and biliary tract admission with major complications (444). For patients undergoing inpatient cholecystectomy without complications, we used the exact DRG costs for the respective procedure without complications (416 and 419). Our model did not classify complications as major or minor. Therefore, for patients who experienced complications, we calculated a weighted cost average of minor and major complications based on the national distribution of major vs. minor complications as available on HCUPnet. ${ }^{16}$ This was done for open and laparoscopic cholecystectomy with complications as well as biliary tract admission with complications. Patients undergoing elective cholecystectomy without complications were presumed to have costs for an outpatient laparoscopic procedure, so we used Ambulatory Payment 
Classification code 0131 for level II laparoscopy, as established by the Centers for Medicare and Medicare Services' Hospital Outpatient Prospective Payment System. ${ }^{17}$ Additional estimates of inpatient hospitalization were obtained from the Agency on Healthcare Research and Quality's Healthcare Cost and Utilization Project "Costs for Hospital Stays in the United States, 2010."18

\section{Utilities (Quality-Adjusted Life Years)}

Table 1 illustrates the utilities for our model. Utility weights were obtained from the Tufts Medical Center Cost-Effectiveness Analysis (CEA) Registry, ${ }^{19}$ or, for data not available, from previous observations in the published literature. ${ }^{20-24}$ The Tufts CEA Registry provides over 14,000 utility measures that are established from a rigorous systematic literature review. We used these data to derive quality-adjusted life years (QALYs) at two years after the initial episode of symptomatic cholelithiasis for multiple health states. A quality-adjusted life year is a measurement of quality of life and ranges from 0 (death or worst health possible) to 1 (perfect quality of life) at one year. QALYs are the standard measurement for utilities in decision analyses. ${ }^{25}$ All of the previously established QALYs used for this study were calculated with a one-year time horizon. As a result, to account for this study's two year timeframe, the QALYs were multiplied by a factor of two, a method that has been illustrated previously. ${ }^{25}$

An incremental cost-effectiveness ratio (ICER) was calculated as: (Costs of elective cholecystectomy-costs of observation)/ (QALY of elective cholecystectomy-QALY of observation). A decision is said to be absolutely dominated if it is both more costly and less effective than an alternative decision; a decision is dominated if it is either more costly or less effective than the alternative.

\section{Model Assumptions}

Our model assumes that only patients with disease of mild severity (not requiring initial or urgent operation/hospital admission) are included. Patients were presumed to maintain a constant quality of life in each disease state for the duration of the immediate two-year period after initial diagnosis. The costs and complications of specific surgical interventions and nonsurgical procedures, such as intraoperative cholangiogram, common bile duct exploration, endoscopic retrograde cholangiopancreatography, and percutaneous transhepatic cholecystostomy, were not considered. Initial outpatient clinic evaluation and/or ED visit costs were deemed to be marginal and not included. Finally, our model also assumes that background mortality for each treatment decision arm (elective cholecystectomy vs. observation) is the same.

\section{Sensitivity Analyses}

Due to the potential for imprecision in cost estimates and the inherent variability of utilities, additional one-way sensitivity analyses were performed for all input parameters using estimates from prior published findings. For cholecystectomy costs, open cholecystectomy charges with major complications were used as the upper limit; for hospital admissions, biliary tract admissions with major complication costs were used. In addition, given the heterogeneous nature of this patient population, a range of operative morbidity and mortality 
probabilities were also entered into the model based on findings from prior large observational studies ${ }^{26-34}$ and one Cochrane review of randomized controlled trials. ${ }^{35}$ Finally, varying QALYs were imputed into model based on prior literature findings (Table 1). ${ }^{19-24}$ One-way threshold analyses were performed for key parameters to determine the point at which the decision model results would change. All analyses were performed using TreeAge Pro 2013 (Williamstown, MA).

\section{RESULTS}

\section{Effectiveness and Cost Effectiveness (Table 2)}

For the base case, observation was the more cost-effective approach. Elective cholecystectomy in all patients was absolutely dominated, meaning that it was both more costly $(+\$ 3,422.83)$ and also resulted in a marginally decreased quality of life at two years (-0.10 QALYs) compared to observation. The ICER was $\$ 35,234 / \mathrm{QALY}$, favoring observation.

\section{Threshold Analysis Based on Probability of Symptoms}

We performed a threshold analysis in order to determine the probability of symptoms at which elective cholecystectomy became more effective and more cost-effective. Elective cholecystectomy became more effective when the probability for recurrent symptoms exceeded $45.3 \%$ (Figure 2A). At this probability, elective cholecystectomy was still more costly, with an additional cost of $\$ 2,191.67$ for performing elective cholecystectomy over observation. Elective cholecystectomy became the more cost-effective option overall when the probability for continued symptoms exceeded $82.7 \%$ (Figure 2B).

\section{Sensitivity Analyses (Table 3)}

Our model was only sensitive to changes in the probability of continued symptoms after observation and the QALYs of elective cholecystectomy at two years. For patients who would hypothetically experience a significant improvement in QALY after elective cholecystectomy at two years (1.94), elective cholecystectomy would become the more effective approach but at an incremental cost of $\$ 3,422.83$ (Figure 3 ). On sensitivity analysis using the low and high range of estimates illustrated in Table 1, elective cholecystectomy remained absolutely dominated for all other model parameters (costs, probabilities, and QALYs).

\section{DISCUSSION}

For older patients presenting with mild biliary disease, if the likelihood for continuing symptoms is greater than $45 \%$, early elective cholecystectomy is the more effective treatment option at an incremental cost of $\$ 2,191$. Performing cholecystectomy in every patient leads to an additional cost of $\$ 3,422$, with a marginal decrease in QALY. As such, observation is more effective and cost-effective for the average older patient whose symptoms are tolerable. Elective cholecystectomy becomes the more cost-effective decision for all patients only when the likelihood of continuing symptoms exceeds $82 \%$. 
A prior qualitative study by McKneally et al. identified dramatic variations in patient perspectives regarding the surgeon's advice on elective cholecystectomy, ranging from extreme suspicion to complete acquiescence. ${ }^{36}$ In addition, many patients indicated that fear of the procedure guided their decision to avoid elective cholecystectomy, in some cases for over twenty years. The study interviews also revealed that many patients harbored a significant mistrust for the healthcare system in general.

This apparent patient anxiety of undergoing elective surgery coupled with the lack of scientific evidence make the development of risk-prediction models paramount to improving healthcare delivery for these patients. The shared decision-making process of when to perform cholecystectomy for the older patient should be precise and evidence-based, but little is known of the natural history of symptomatic cholelithiasis for these patients. This decision is even more difficult in older patients, in whom coexisting chronic illness increases operative risk while simultaneously decreasing the likelihood of gallstone related complications due to progression and death from these other illnesses. A prior study by Quintana et al. using RAND appropriateness methodology attempted to determine what factors should be considered when modeling the decision to perform elective cholecystectomy. ${ }^{37}$ Expert panelist opinion and an extensive literature review yielded the conclusion that the benefits of elective cholecystectomy are generally uncertain for these older patients who have multiple comorbidities. This study also fell short of qualifying the precise risks and benefits of cholecystectomy vs. observation in an older population with mild biliary disease.

Our decision model provides a probability for recurrent symptoms at which early elective cholecystectomy is both effective and cost-effective in the average older patient with mild biliary disease. In a previous study evaluating the natural history of older patients with untreated symptomatic cholelithiasis (no cholecystectomy) we derived a prognostic nomogram which reliably identified approximately $10 \%$ of older patients with incident symptomatic gallstones who had over a $>40 \%$ 2-year risk of developing gallstone-related complications and an additional $50 \%$ of patients with less than $10 \%$-year risk. ${ }^{12}$ This nomogram is based on readily identifiable preoperative characteristics including gender, comorbid illness, initial presentation to the emergency department, and presence of complicated biliary disease such as gallstone pancreatitis or choledocholithiasis. These cases represent high-risk populations and, for this subpopulation of older patients, early elective cholecystectomy is likely the more effective and less costly option, as their likelihood for recurrent symptoms is high.

This prior study provides readily identifiable characteristics that practitioners may use to calculate a precise probability estimate at which patients may experience recurrent symptoms. This probability estimate, coupled with the findings from our decision analysis, can be used to provide individual risk assessment, decreasing patient anxiety and balancing the risks of undergoing elective cholecystectomy with the potential risk of developing future biliary complications. These data allow practitioners to provide patients with specific information that is currently not easily accessible at the time of consultation, allowing for more informed decision making. For instance, for some older patients who may wish to avoid surgery, a risk $>40 \%$ may not seem worrisome, while to others, this risk may be 
untenable. The decision of when to undergo cholecystectomy will thereby ultimately be a balance of the probability estimates our data provide and unique patient preferences.

Our model was derived to address a very specific clinical question for a marginal population of older patients in whom the benefits of cholecystectomy may be uncertain, and our findings should be taken in this specific context. The cohort from which probabilities were derived excluded patients in whom elective cholecystectomy was performed within 2.5 months of initial presentation with symptomatic cholelithiasis. As such, it should be made clear that even in a patient with lower risk of developing complications in whom symptoms are adversely impacting quality of life and surgery is reasonable risk, cholecystectomy should be offered.

Our study has several limitations. We did not assess the impact of adjunctive measures such as endoscopic retrograde cholangiogram and percutaneous transhepatic cholangiography that may alter a patient's treatment course. In addition, our model makes many other assumptions (as listed previously) that may have potentially affected our study results. The use of QALYs in our model can be subjective and may vary widely amongst patients, but we performed additional sensitivity analyses using varying QALYs. We also used cost estimates from the perspective a third party payer and these costs may also vary. By including sensitivity analyses with varying costs we also hoped to mitigate the effects of cost variation on our study findings. As a result, the findings of our study may not always be applicable to each individual patient and practice decisions should be tailored to each clinical circumstance. For instance, our decision model is not applicable to patients who have obvious indications for cholecystectomy or patients who may clearly be observed safely.

\section{CONCLUSION}

Our findings suggest that older patients with mild biliary disease benefit from early elective cholecystectomy when there is a high suspicion for recurrent illness. These data can be used to guide shared decision-making in older patients presenting with symptomatic cholelithiasis. Treatment decisions should be individualized on a case-by-case basis and shared with each patient. This data driven, patient-centered approach has the potential to streamline the decision-making process for individual older adults while improving outcomes at the population level for all.

\section{Acknowledgments}

None.

Funding: Supported by grants from the UTMB Clinical and Translational Science Award \#UL1TR000071, NIH T-32 Grant \# 5T32DK007639, and AHRQ Grant \# 1R24HS022134.

\section{References}

1. Thistle JL, Cleary PA, Lachin JM, et al. The natural history of cholelithiasis: the National Cooperative Gallstone Study. Ann Intern Med. 1984; 101(2):171-5. [PubMed: 6742647]

2. Shaffer EA. Epidemiology and risk factors for gallstone disease: has the paradigm changed in the 21st century? Curr Gastroenterol Rep. 2005; 7(2):132-40. [PubMed: 15802102] 
3. Sanson TG, O'Keefe KP. Evaluation of abdominal pain in the elderly. Emerg Med Clin North Am. 1996; 14(3):615-27. [PubMed: 8681887]

4. Gurusamy KS, Samraj K, Fusai G, et al. Early versus delayed laparoscopic cholecystectomy for biliary colic. Cochrane Database Syst Rev. 2008; 4:CD007196. [PubMed: 18843746]

5. Gallstones and laparoscopic cholecystectomy. NIH Consens Statement. 1992; 10(3):1-28.

6. Schmidt M, Søndenaa K, Vetrhus M, et al. A randomized controlled study of uncomplicated gallstone disease with a 14-year follow-up showed that operation was the preferred treatment. Dig Surg. 2011; 28(4):270-6. [PubMed: 21757915]

7. Riall TS, Zhang D, Townsend CM, et al. Failure to perform cholecystectomy for acute cholecystitis in elderly patients is associated with increased morbidity, mortality, and cost. J Am Coll Surg. 2010; 210(5):668-77. 677-9. [PubMed: 20421027]

8. Arthur JD, Edwards PR, Chagla LS. Management of gallstone disease in the elderly. Ann R Coll Surg Engl. 2003; 85(2):91-6. [PubMed: 12648337]

9. Bergman S, Sourial N, Vedel I, et al. Gallstone disease in the elderly: are older patients managed differently? Surg Endosc. 2011; 25(1):55-61. [PubMed: 20512508]

10. Portincasa P, Moschetta A, Petruzzelli M, et al. Gallstone disease: Symptoms and diagnosis of gallbladder stones. Best Pract Res Clin Gastroenterol. 2006; 20(6):1017-29. [PubMed: 17127185]

11. Festi D, Reggiani ML, Attili AF, et al. Natural history of gallstone disease: Expectant management or active treatment? Results from a population-based cohort study. J Gastroenterol Hepatol. 2010; 25(4):719-24. [PubMed: 20492328]

12. Parmar A, Sheffield K, Adhikari D, et al. PREOP-Gallstones: A Prognostic Nomogram for the Management of Symptomatic Cholelithiasis in Older Patients. Annals of Surgery. Accepted for publication, April 2014.

13. Sommers BD, Bindman AB. New physicians, the Affordable Care Act, and the changing practice of medicine. JAMA. 2012; 307(16):1697-8. [PubMed: 22535852]

14. 2013 Annual Report of the Boards of Trustees of Federal Hospital Insurance and Federal Supplementary Medical Insurance Trust Funds. The Henry J. Kaiser Family Foundation; 2013.

15. Quality AfHRa. HCUPnet 2014. Accessed 19 March, 2014

16. HCUPnet 2014. Available at: http://hcupnet.ahrq.gov/. Accessed 19 March, 2014

17. Hospital Outpatient Prospective Payment System 2013. Available at: http://www.cms.gov/ Medicare/Medicare-Fee-for-Service-Payment/HospitalOutpatientPPS/index.html. Accessed 19 March, 2014

18. Pfuntner, A.; Wier, LM.; Steiner, C. Costs for Hospital Stays in the United States, 2010 [Healthcare Cost and Utilization Project web site]. 2013. Available at: http://hcup-us.ahrq.gov/ reports/statbriefs/sb146.pdf. Accessed October, 2013

19. Cost-Effectiveness Analysis Registry. Tufts Medical Center: Center for the Evaluation of Value and Risk in Health; 2007-2013.

20. Bass EB, Pitt HA, Lillemoe KD. Cost-effectiveness of laparoscopic cholecystectomy versus open cholecystectomy. Am J Surg. 1993; 165(4):466-71. [PubMed: 8480883]

21. Bass EB, Steinberg EP, Pitt HA, et al. Comparison of the rating scale and the standard gamble in measuring patient preferences for outcomes of gallstone disease. Med Decis Making. 1994; 14(4): 307-14. [PubMed: 7808206]

22. Johner A, Raymakers A, Wiseman SM. Cost utility of early versus delayed laparoscopic cholecystectomy for acute cholecystitis. Surg Endosc. 2013; 27(1):256-62. [PubMed: 22773234]

23. Macafee DA, Humes DJ, Bouliotis G, et al. Prospective randomized trial using cost-utility analysis of early versus delayed laparoscopic cholecystectomy for acute gallbladder disease. Br J Surg. 2009; 96(9):1031-40. [PubMed: 19672930]

24. Wilson E, Gurusamy K, Gluud C, et al. Cost-utility and value-of-information analysis of early versus delayed laparoscopic cholecystectomy for acute cholecystitis. Br J Surg. 2010; 97(2):2109. [PubMed: 20035545]

25. Birkmeyer JD, Welch HG. A reader's guide to surgical decision analysis. J Am Coll Surg. 1997; 184(6):589-95. [PubMed: 9179115] 
26. Brunt LM, Quasebarth MA, Dunnegan DL, et al. Outcomes analysis of laparoscopic cholecystectomy in the extremely elderly. Surg Endosc. 2001; 15(7):700-5. [PubMed: 11591971]

27. Feldman MG, Russell JC, Lynch JT, et al. Comparison of mortality rates for open and closed cholecystectomy in the elderly: Connecticut statewide survey. J Laparoendosc Surg. 1994; 4(3): 165-72. [PubMed: 7919503]

28. Firilas A, Duke BE, Max MH. Laparoscopic cholecystectomy in the elderly. Surg Endosc. 1996; 10(1):33-5. discussion 36. [PubMed: 8711602]

29. Ho HS, Mathiesen KA, Wolfe BM. The impact of laparoscopic cholecystectomy on the treatment of symptomatic cholelithiasis. Surg Endosc. 1996; 10(7):746-50. [PubMed: 8662432]

30. Ruhl CE, Everhart JE. Gallstone disease is associated with increased mortality in the United States. Gastroenterology. 2011; 140(2):508-16. [PubMed: 21075109]

31. Schwesinger WH, Sirinek KR, Strodel WE. Laparoscopic cholecystectomy for biliary tract emergencies: state of the art. World J Surg. 1999; 23(4):334-42. [PubMed: 10030856]

32. Scollay JM, Mullen R, McPhillips G, et al. Mortality associated with the treatment of gallstone disease: a 10-year contemporary national experience. World J Surg. 2011; 35(3):643-7. [PubMed: 21181471]

33. Tagle FM, Lavergne J, Barkin JS, et al. Laparoscopic cholecystectomy in the elderly. Surg Endosc. 1997; 11(6):636-8. [PubMed: 9171122]

34. Zacks SL, Sandler RS, Rutledge R, et al. A population-based cohort study comparing laparoscopic cholecystectomy and open cholecystectomy. Am J Gastroenterol. 2002; 97(2):334-40. [PubMed: 11866270]

35. Keus F, Gooszen HG, van Laarhoven CJ. Open, small-incision, or laparoscopic cholecystectomy for patients with symptomatic cholecystolithiasis. An overview of Cochrane Hepato-Biliary Group reviews. Cochrane Database Syst Rev. 2010; 1:CD008318. [PubMed: 20091665]

36. McKneally MF, Ignagni E, Martin DK, et al. The leap to trust: perspective of cholecystectomy patients on informed decision making and consent. J Am Coll Surg. 2004; 199(1):51-7. [PubMed: 15217630]

37. Quintana JM, Cabriada J, de Tejada I, et al. Development of explicit criteria for cholecystectomy. Qual Saf Health Care. 2002; 11(4):320-6. [PubMed: 12468691] 


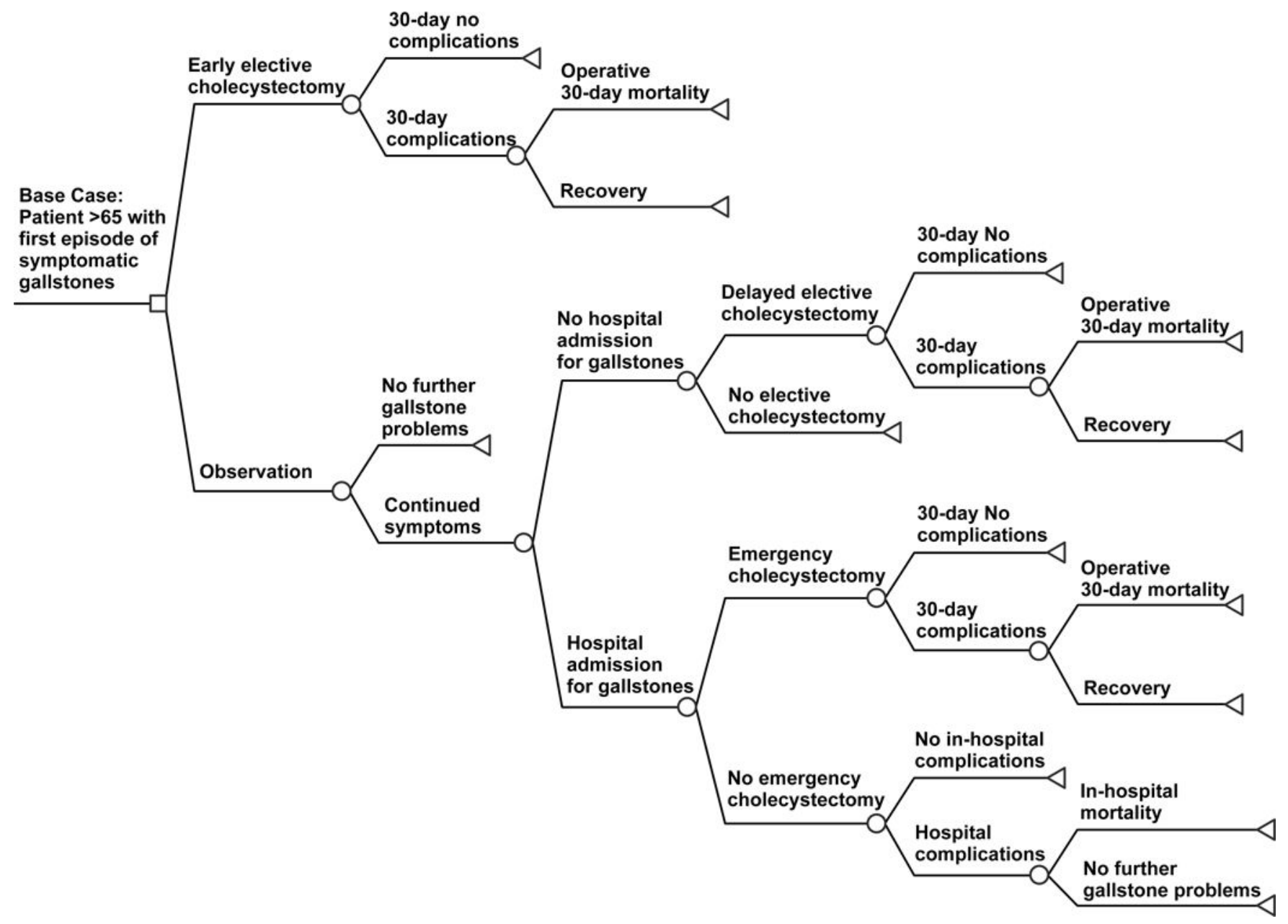

Figure 1.

Cost-effectiveness decision tree for a patient older than 65 presenting with mild symptomatic cholelithiasis. Only patients with mild symptoms not requiring early cholecystectomy or hospitalization were considered for the model. 

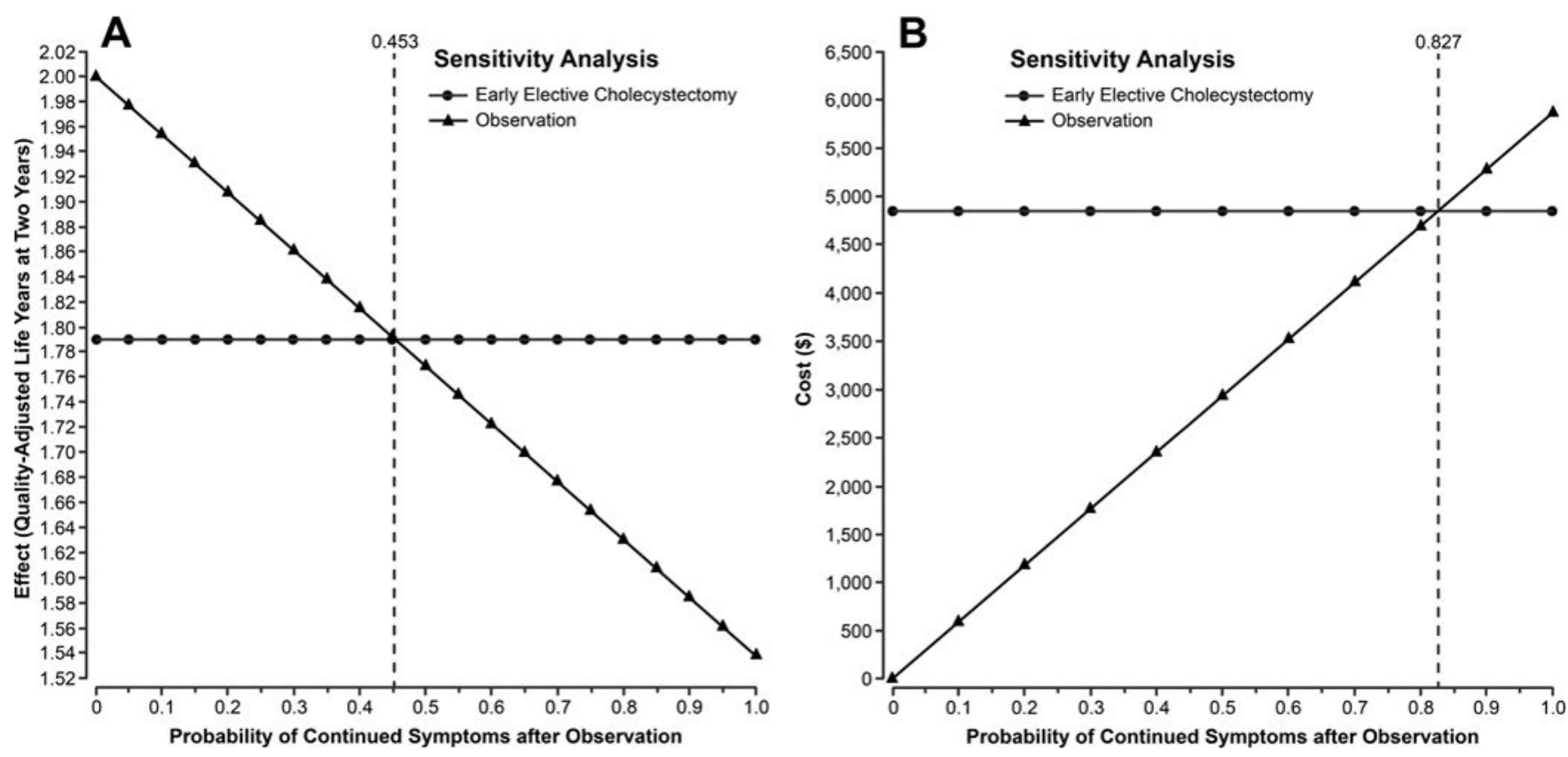

Figure 2.

Figure 2A. Sensitivity analysis, probability for continued symptoms after initial presentation of mild biliary disease. When the probability for continued symptoms exceeded 0.45 , early elective cholecystectomy became the more effective option.

Figure 2B. Sensitivity analysis, probability for continued symptoms after initial presentation of mild biliary disease. When the probability for continued symptoms exceeded 0.83 , early elective cholecystectomy became the less costly option. 


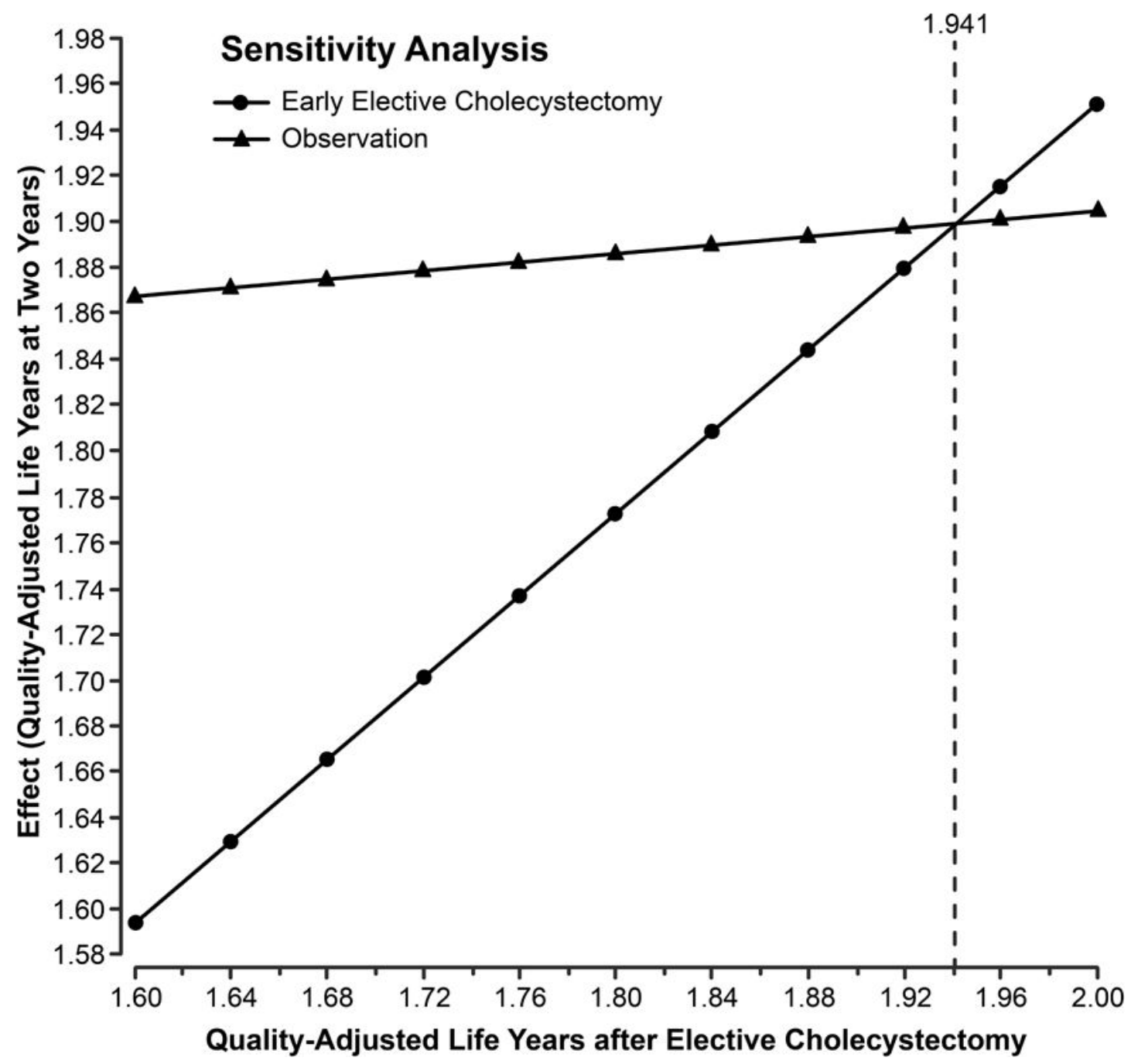

Figure 3.

Sensitivity analysis, quality-adjusted life years for elective cholecystectomy at two years after initial presentation of mild biliary disease. When the quality-adjusted life years for elective cholecystectomy exceeded 1.94 , early elective cholecystectomy became the more effective option. 


\section{Table 1}

Summary of Probabilities, Costs and Utilities.

\begin{tabular}{|c|c|c|c|}
\hline Variable & Base & Low & High \\
\hline \multicolumn{4}{|l|}{ Probabilities $^{26,27,29-33}$} \\
\hline \multicolumn{4}{|l|}{ Elective Cholecystectomy } \\
\hline Morbidity & 0.105 & 0 & 1 \\
\hline Mortality & 0.0004 & 0 & 1 \\
\hline \multicolumn{4}{|l|}{ Observed Patients } \\
\hline Continued Symptoms & 0.243 & 0 & 1 \\
\hline Hospital Admission Given Symptoms & 0.457 & 0 & 1 \\
\hline Hospital Morbidity & 0.565 & 0 & 1 \\
\hline Hospital Mortality & 0.0614 & 0 & 1 \\
\hline Emergent Cholecystectomy & 0.830 & & \\
\hline Morbidity & 0.268 & 0 & 1 \\
\hline Mortality & 0.012 & 0 & 1 \\
\hline \multicolumn{4}{|l|}{ Costs $^{16,18}$} \\
\hline Outpatient Elective Cholecystectomy, No Complications & $\$ 3,487$ & $\$ 1,957$ & $\$ 9,826$ \\
\hline Elective Cholecystectomy With Complications & $\$ 16,433$ & $\$ 13,240$ & $\$ 27,200$ \\
\hline Hospital Admission for Biliary Tract Disease, No Complications & $\$ 6,273$ & $\$ 6,273$ & $\$ 12,786$ \\
\hline Hospital Admission for Biliary Tract Disease, With Complications & $\$ 10,203$ & $\$ 8,553$ & $\$ 12,786$ \\
\hline Hospital Admission with Emergent Cholecystectomy, No Complications & $\$ 10,033$ & $\$ 9,826$ & $\$ 11,525$ \\
\hline Hospital Admission with Emergent Cholecystectomy, With Complications & $\$ 16,433$ & $\$ 13,240$ & $\$ 27,200$ \\
\hline Continuing Symptoms & 0 & N/A & N/A \\
\hline \multicolumn{4}{|l|}{ Utilities } \\
\hline \multicolumn{4}{|l|}{ Quality-Adjusted Life Years (QALY) at Two Years ${ }^{19-24}$} \\
\hline Elective Cholecystectomy & 1.82 & 1.6 & 2.0 \\
\hline Continued Symptoms & 1.3 & 0.8 & 1.6 \\
\hline Complications of Emergency Cholecystectomy & 1.54 & 1.0 & 1.6 \\
\hline Hospital Admission & 1.54 & 1.3 & 1.9 \\
\hline Hospital Admission with Complications & 1.36 & 1.0 & 1.6 \\
\hline
\end{tabular}




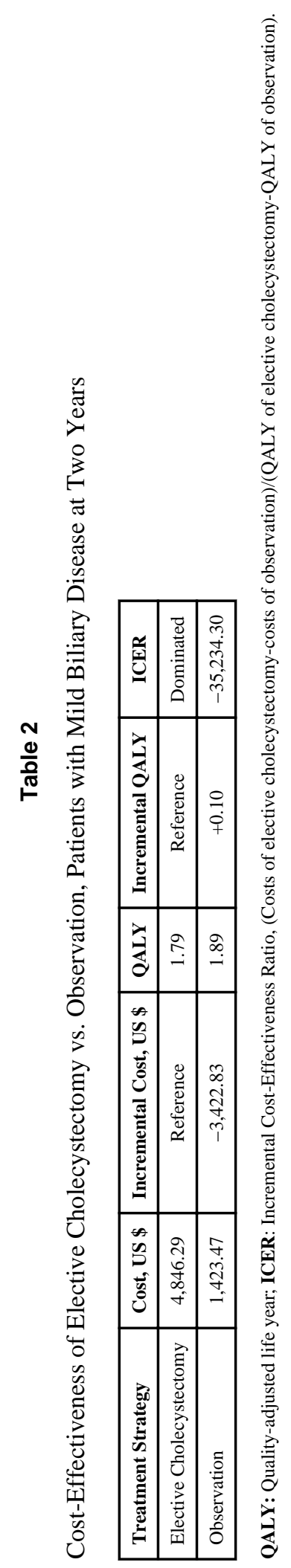

J Gastrointest Surg. Author manuscript; available in PMC 2015 September 01. 


\section{Table 3}

Sensitivity Analyses, One-way Threshold Analyses for Effectiveness and Cost-Effectiveness ${ }^{a}$

\begin{tabular}{|l|c|c|c|}
\hline Value & Range & $\begin{array}{c}\text { Effectiveness Threshold } \\
\text { (Incremental cost) }\end{array}$ & Cost-Effectiveness Threshold \\
\hline Probabilities & & & \\
\hline Continued Symptoms if Observed & $0-1$ & $0.45(\$ 2,192)$ & 0.83 \\
\hline Utilities [Quality-Adjusted Life Years (QALY) at Two Years] & & & \\
\hline Elective Cholecystectomy* & $1.6-2.0$ & $1.94(\$ 3,423)$ & N/A \\
\hline
\end{tabular}

${ }^{a}$ Observation was the more cost-effective option for all older patients with mild biliary disease. Shown are values for model parameters at which model results changed. For instance, when the probability for continued symptoms exceeded 0.45 or the QALY for elective cholecystectomy exceeded 1.94, elective cholecystectomy became the more effective option. The model was insensitive to variations in other parameters. 